\title{
ПРОБЛЕМЫ И ПУТИ РЕШЕНИЙ В ХОДЕ РЕАЛИЗАЦИИ СИСТЕМЫ КАЗНАЧЕЙСКИХ ПЛАТЕЖЕЙ В СУБЪЕКТАХ РОССИЙСКОЙ ФЕДЕРАЦИИ (НА ПРИМЕРЕ ЛЕНИНГРАДСКОЙ ОБЛАСТИ)
}

\section{PROBLEMS AND SOLUTIONS DURING THE IMPLEMENTATION OF THE TREASURY PAYMENTS SYSTEM IN THE SUBJECTS OF THE RUSSIAN FEDERATION (ON THE EXAMPLE OF THE LENINGRAD REGION)}

\section{A. Ermolenko}

Summary. This article outlines the range of problems identified during the transition to the system of treasury payments from the financial authorities of the constituent entities of the Russian Federation (for example, the Leningrad Region), which independently carry out the execution of the budgets of the constituent entities of the Russian Federation, in the conditions of opening a personal account with a financial authority in the Federal Treasury. The options of treasury services for the execution of regional budgets are considered, taking into account the subsidization of the regions. It is concluded that the non-subsidized constituent entities of the Russian Federation carry out the execution of budgets independently. It was found that in the Leningrad region, with the independent budget execution in the UFK in the Leningrad region, with the transfer of part of the powers of the financial body for servicing budgetary and autonomous institutions to the territorial body of the federal treasury, the main problem in the implementation of the treasury payment system is the technical component.

Keywords: treasury payment system, financial authorities of subjects of the Russian Federation, transfer of powers, information systems, treasury account, execution of budgets of subjects of the Russian Federation, treasury service, financial authorities of subjects of the Russian Federation.

\author{
Ермоленко Анна Владимировна \\ Начальник отдела, Комитет финансов \\ Ленинградской области \\ ankin2002@mail.ru
}

Аннотация. В данной статье очерчен круг проблем, выявленных при переходе на систему казначейских платежей у финансовых органов субъектов Российской Федерации (на примере Ленинградской области), которые самостоятельно осуществляют исполнение бюджетов субъектов Российской, в условиях открытия лицевого счёта финансовому органу в Федеральном казначействе. Рассмотрены варианты казначейского обслуживания исполнения региональных бюджетов, учетом дотационности регионов. Сделаны выводы о том, что недотационные субъекты Российской Федерации осуществляют исполнение бюджетов самостоятельно. Установлено, что в Ленинградской области, при самостоятельном исполнении бюджета в УФК по Ленинградской области, с передачей части полномочий финансового органа по обслуживанию бюджетных и автономных учреждений в территориальный орган федерального казначейства, основной проблемой в ходе реализации системы казначейских платежей является техническая составляющая.

Ключевые слова: казначейская система платежей, финансовые органы субъектов РФ, передача полномочий, информационные системы, казначейский счет, исполнение бюджетов субъектов РФ, казначейское обслуживание, финансовые органы субъектов РФ.
C 1 января 2021 года вступили в силу положения Федерального закона № 479-Ф3 от 27 декабря 2019 года «О внесении изменений в Бюджетный кодекс Российской Федерации в части казначейского обслуживания и системы казначейских платежей» (далее - 479-Ф3), согласно которым система казначейских платежей (далее - СКП) представляет собой совокупность участников и оператора системы казначейских платежей, взаимодействующих по правилам организации и функционирования системы казначейских пла- тежей. Главными членами проекта СКП являются Минфин России, Центральный Банк Российской Федерации, на которые возложены обязанности установления взаимодействия СКП с платежными системами и Федеральное казначейство, как оператор СКП, обеспечивающий функционирование СКП и связанные с этим операции.

Бюджетным кодексом Российской Федерации (далее - БК) определено, что прямые участники СКП - это Федеральное казначейство и его территориальные орга- 
ны (ТОФК), финансовые органы субъекта Российской Федерации (далее - СРФ, РФ), органы управления государственными внебюджетными фондами, администраторы доходов бюджетов, получатели средств федерального бюджета, получатели средств бюджета территориального государственного внебюджетного фонда, администраторы источников финансирования дефицита федерального бюджета, администраторы источников финансирования дефицита бюджета территориального государственного внебюджетного фонда, федеральные бюджетные и автономные учреждения, юридические лица, не являющиеся участником бюджетного процесса, бюджетными и автономными учреждениями, лицевые счета которым открыты в Федеральном казначействе.

Косвенными участниками СКП, при самостоятельном исполнении бюджета СРФ (местного бюджета), с открытием лицевого счета финансовому органу СРФ (местного бюджета), являются получатели средств бюджета СРФ (местного бюджета), бюджета государственного внебюджетного фонда РФ, администраторы источников финансирования дефицита бюджета СРФ (местного бюджета), бюджета государственного внебюджетного фонда РФ, бюджетные и автономные учреждения СРФ (муниципальные бюджетные и автономные учреждения), юридические лица, не являющиеся участником бюджетного процесса, бюджетными и автономными учреждениями, лицевые счета которым открыты в финансовом органе СРФ (муниципального образования). В случае передачи Федеральному казначейству отдельных функций финансового органа СРФ (муниципального образования), органа управления государственным внебюджетным фондом РФ, все вышеперечисленные косвенные участники СКП являются прямыми участниками СКП.

На примере Ленинградской области, где принято решение о самостоятельном исполнении областного бюджета Ленинградской области, с открытием лицевого счета Комитету финансов Ленинградской области (далее - КФ ЛО) в Управлении Федерального казначейства по Ленинградской области (далее - УФК по ЛО), с одновременной передачей в УФК по ЛО функций по проведению и санкционированию операций по расходам бюджетных и автономных учреждений Ленинградской области, прямые участники СКП - это УФК по ЛО, КФ ЛО, косвенные участники СКП - это получатели средств областного бюджета Ленинградской области, администраторы источников финансирования дефицита областного бюджета Ленинградской области и юридические лица, не являющиеся участниками бюджетного процесса, бюджетными и автономными учреждениями, лицевые счета которым открыты в КФ ЛО.

Согласно требованиям БК денежные средства бюджетов, денежные средства, поступающие во времен- ное распоряжение получателей бюджетных средств, денежные средства бюджетных и автономных учреждений, денежные средства юридических лиц, не являющихся участниками бюджетного процесса, бюджетными и автономными учреждениями, лицевые счета которым открыты в Федеральном Казначействе или финансовом органе СБР, с 1 января 2021 года учитываются только на казначейских счетах. Банковские счета финансовых органов, открытые ранее в Центральном Банке РФ должны быть закрыты. В результате все операции с бюджетными средствами осуществляются через казначейские счета, открытые в Федеральном казначействе.

Положения БК, с учетом изменений 479-Ф3 устанавливают следующие понятия счетов при СКП: казначейский счет - это счет, открытый в Федеральном казначействе (ТОФК) отдельному участнику СКП для осуществления и отражения в СКП операций участника СКП с денежными средствами; единый казначейских счет - это банковский счет, открытый Федеральному казначейству (ТОФК) в Центральном банке РФ в валюте РФ для совершения перевода денежных средств в целях обеспечения осуществления и отражения операций на казначейских счетах, за исключением, казначейских счетов для осуществления и отражения операций с денежными средствами Фонда национального благосостояния; единый счет бюджета - казначейский счет, открытый в Федеральном казначействе отдельно по каждому СРФ для осуществления и отражения операций с денежными средствами по поступлениям в бюджет и перечислениями из бюджета.

Участники СКП (прямые и косвенные) осуществляют операции по казначейским счетам, путем представления распоряжений от прямых участников - оператору СКП (Федеральному казначейству, ТОФК), от косвенных участников - прямым участникам, что в целом представляет процесс осуществления казначейских платежей.

При этом, СКП предусматривает замену действующих «платежных документов», таких как заявка на кассовый расход, заявка на получение наличных денег и так далее на четыре вида распоряжений о совершении казначейских платежей (о перечислении, о возврате, об обеспечении наличными денежными средствами, об уточнении). Данное положение планируется к вступлению в силу с 1 января 2023 года. Таким образом, Федеральное казначейство предоставляет возможность подготовиться в локальных информационных системах к новым форматам «платежных документов».

В новой редакции БК вместо понятия кассовое обслуживание установлено казначейское обслуживание - это проведением Федеральным казначейством 


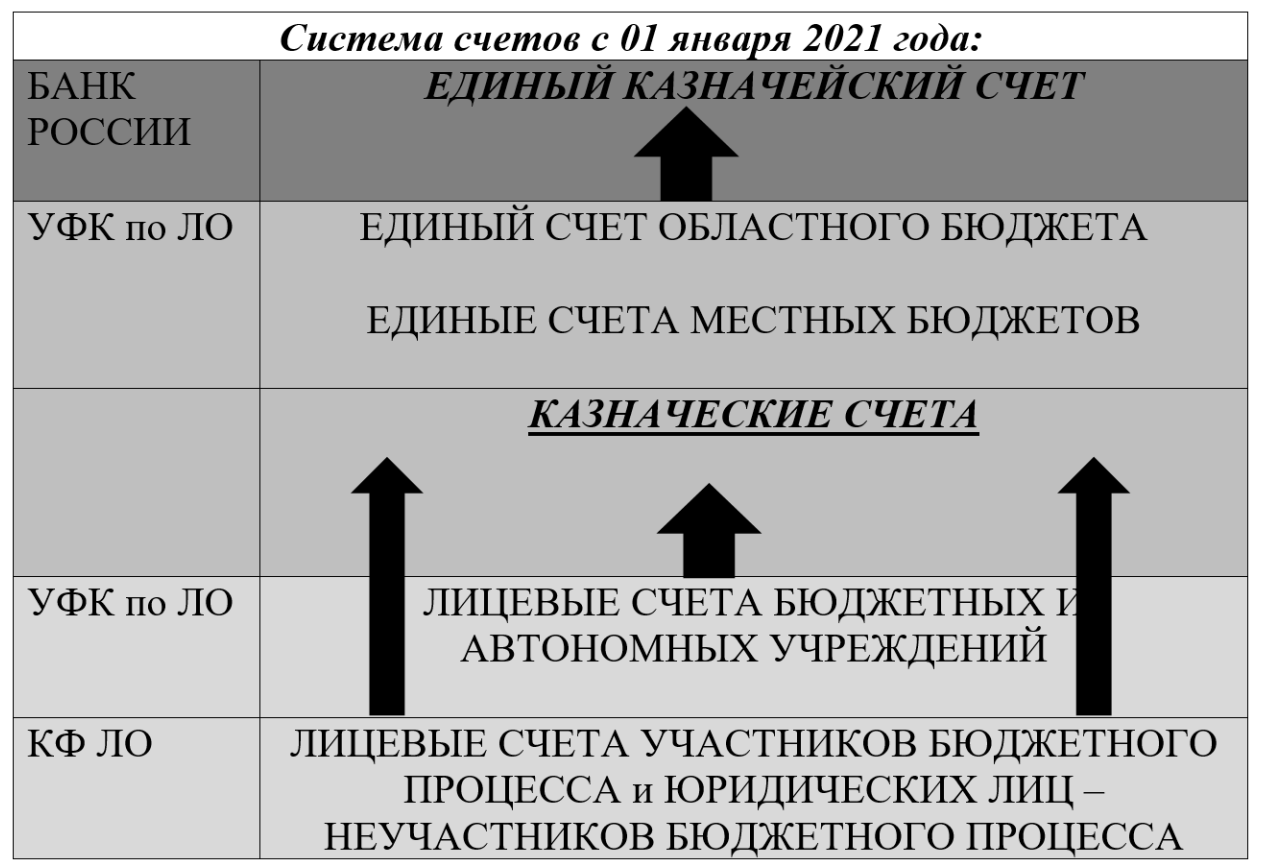

Рис. 1. Схема системы казначейских счетов на примере Ленинградской области

в СКП операций участников СКП с денежными средствами и их отражение на соответствующих казначейских счетах. Казначейское обслуживание исполнения бюджетов бюджетной системы РФ осуществляет Федеральное казначейство (ТОФК).

В действующей редакции БК предусмотрено три варианта казначейского обслуживания исполнения бюджетов СРФ. Высший орган исполнительной власти СРФ, администрация муниципального образования, вправе был выбрать и изменить в последующем любой из нижеперечисленных вариантов казначейского обслуживания исполнения бюджета СРФ (местного бюджета):

1. С открытием лицевого счета бюджета финансовому органу.

2. С открытием лицевых счетов участникам бюджетного процесса уровня СРФ в соответствии с заключенным между органом Федерального казначейства и высшим исполнительным органом государственной власти СБР Соглашением об осуществлении органом Федерального казначейства отдельных функций по исполнению бюджета СРФ, местного бюджета.

3. «Смешанный» порядок казначейского обслуживания исполнения бюджета СРФ.

БК, сучетом редакции 479-Ф3, регламентирует казначейское исполнение бюджетов всех уровней и предусматривает возможность реализации только двух вариантов организации казначейского исполнения региональных бюджетов в рамках функционирования единого счета бюджета:
- передача Федеральному казначейству (ТОФК) проведения операций с условием открытия и ведения лицевых счетов участников бюджетного процесса и неучастников бюджетного процесса его ТОФК (вариант 1);

- проведение Федеральным казначейством (ТОФК) операций со средствами бюджета в условиях открытия и ведения лицевых счетов участников бюджетного процесса и неучастников бюджетного процесса финансовыми органами СРФ (вариант 2).

Важно отметить, что изменение термина с кассового обслуживания на казначейское обслуживание не поменяло логики и обоснованности мер, применяемых в ходе исполнения бюджетов СРФ, где организующую роль выполняют финансовые органы СРФ. Применение «смешанного» порядка казначейского обслуживания СРФ и местными бюджетами с 01 января 202 года исключено. То есть, высший орган исполнительной власти СРФ (местная администрация) должны выступить с обращением о передачи отдельных функций финансового органа СРФ (финансового органа муниципального образования) в Федеральное казначейство (ТОФК). Фактически, финансовый орган СРФ (местная администрация) должны указать вариант 1 или вариант 2 казначейского обслуживания исполнения бюджетов.

Вместе с тем, бюджетным законодательством установлено жесткое ограничение в части предоставления СРФ права самостоятельного осуществления функций 


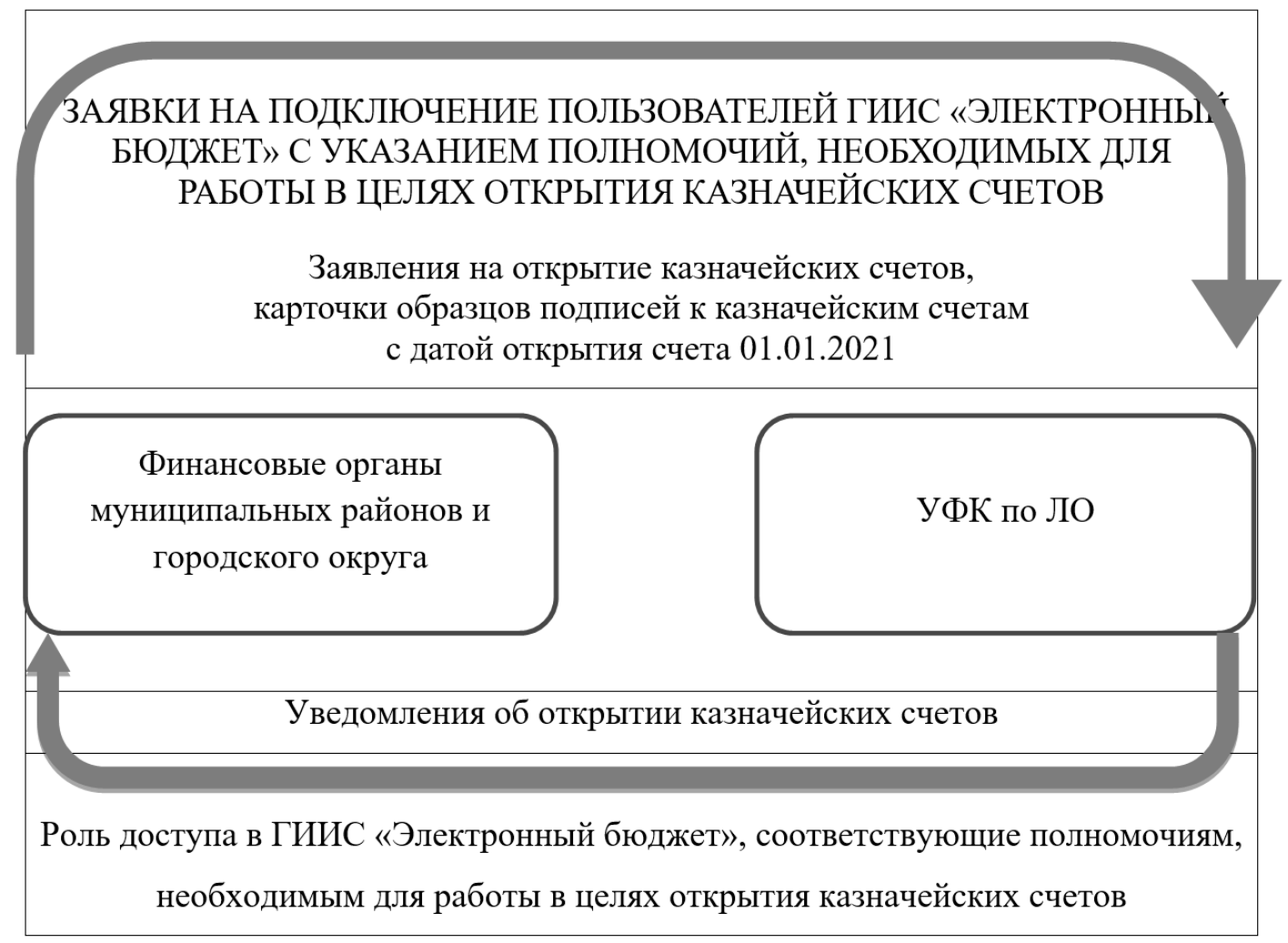

Рис. 2. Порядок открытия казначейских счетов, организованный в Ленинградской области

по открытию и ведению лицевых счетов бюджетополучателей финансовым органом. СРФ обязан передать Федеральному казначейству процедуры по казначейскому исполнению бюджета по варианту открытия и ведения лицевых счетов бюджетополучателей в ТОФК в случае, если доля дотаций из федерального бюджета в бюджет СРФ в течение двух из трех последних отчетных финансовых лет превышала 40 процентов объема доходов консолидированного бюджета СРФ. По данным Казначейства России только 18 субъектов РФ осуществляют организацию казначейского исполнения бюджета по варианту 2, в число которых входит и Ленинградская область.

Согласно утвержденным Минфином перечням СРФ по распределению дотаций на выравнивание бюджетной обеспеченности субъектам РФ на 2021 год и плановый период 2021 и 2022 годов, не являются получателями дотаций 13 СРФ из 85. Это Республика Татарстан, Калужская, Ленинградская, Московская, Самарская, Сахалинская, Свердловская, Тюменская области, города федерального значения Москва и Санкт-Петербург, Ненецкий, Ханты-Мансийский (Югра), Ямало-Ненецкий автономные округа. При этом практически все вышеуказанные обеспеченные СРФ, за исключением Ненецкого автономного округа, осуществляют казначейское обслуживание исполнения бюджета СРФ по варианту 2, в рамках открытия лицевого счета бюджета СРФ финансовому органу.
В Ленинградской области, в целях перехода на казначейское обслуживание и систему казначейских платежей был разработан План мероприятий («Дорожная карта»), в которой по двум блокам был установлен алгоритм действий КФ ЛО и участников, включай ожидаемый эффект, сроки реализации и ответственных исполнителей в КФ ЛО. Так, был определен организационный блок, в рамках которого установлены организационные мероприятия, направленные на адаптацию работы в информационной системе Ленинградской области (ИС УБП) с интеграцией данных в Государственную интегрированную информационную систему управления общественными финансами «Электронный бюджет». Второй блок был направлен на мероприятия по внесению изменений и разработку нормативной базы для реализации СКП.

На Московском финансовом форуме - 2021, на пленарном заседании, посвященного СКП, в рамках нового этапа казначейской системы, отмечалось, что реализация СКП считается самым масштабным и сложным проектом главных членов СКП за последние 20 лет. Были обозначены суть проекта СКП и предварительные итоги. Так, суть проекта СКП, при кратком изложении заключается в:

1. Централизации и концентрации средств государственного сектора экономики Российской 


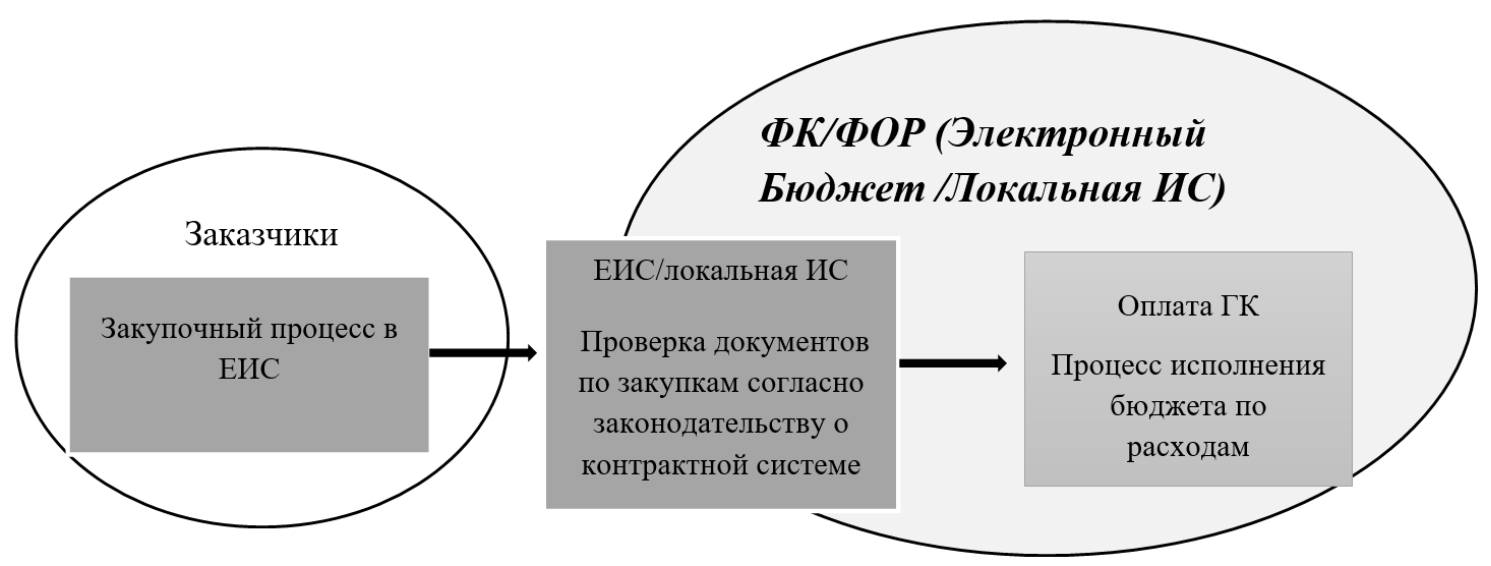

Рис. 3. Схема процессов по осуществлению закупок и исполнению бюджета по расходам посредством информационных систем

Федерации (далее - РФ) на едином казначейском счете;

2. Ускорение оборачиваемости средств государственного сектора экономики и оптимизации заимствования с этим связанного;

3. Реализация развития периметра и технологии CASH- менеджмента и управление финансовыми ресурсами в целом.

Предварительные итоги проекта СКП заключаются в:

1. Завершение десятилетнего этапа проекта Федерального казначейства «Модернизация казначейской системы», в рамках которого осуществлена полная модернизации нормативной базы, технической базы, с созданием единой казначейской телекоммуникационной сети, что позволило в настоящем обеспечить сосредоточение на едином казначейском счете всех средств, включая средств 85 СРФ, 22,5 тыс. бюджетов муниципальных образований, то есть всего государственного сектора.

2. В социальном эффекте: ускорение оборачиваемости бюджетных средств, оптимизация заимствования и управления средствами.

Проблемы возникающие у СРФ в ходе реализации СКП, на примере Ленинградской области. В Ленинградской области, в условиях выбранного самостоятельного исполнения бюджета, одной из главной проблем является техническая составляющая. КФ ЛО организует процесс исполнения областного бюджета в локальной информационной системе «Управление бюджетным процессом». Разработанный отдельный модуль на базе ИС УБП «Государственный заказ Ленинградской области» осуществляет интеграцию с Единой информационной системой в сфере закупок и ГИИС «Электронный бюджет». Оператором последних перечисленных систем является Федеральное казначейство. На сегодняшний день ГИИС «Электронный бюджет» охватывает практически все области управления бюджетными средствами и реализован в подсистемах бюджетного планирования, управления закупками, управления расходами, финансового контроля, нормативно-справочной информации, информационно-аналитического обеспечения.

Так, необходимым условием бесперебойного функционирования казначейской системы в рамках реализации СКП полная интеграция процессов исполнения бюджетов СРФ (местных бюджетов) с единой информационной системой в сфере закупок и ГИИС «Электронный бюджет».

В Ленинградской области на последнем этапе находится масштабная перестройка, направленная на совершенствование информационной системы, которая обеспечивает работу всех муниципальных образований, включая передачу полномочий по обслуживанию городских и сельских поселений на уровень района, и Правительства Ленинградской области, в едином информационном облаке - ИС УБП.

Таким образом, реализация СКП в СРФ, которые самостоятельно осуществляют бюджет СРФ обеспечивается посредством организующей роли финансового органа СРФ, который обязан обеспечить как методологическую базу, так и техническую составляющую, в рамках заданного направления при казначейском обслуживании Федеральным казначейством (ТОФК). При этом, изменения термина «кассовое обслуживание» на «казначейское обслуживание» не поменяло логики и последовательности мер в ходе исполнения бюджета СРФ и главным направлением в целях повышения эффективности исполнения бюджетов СРФ (местных бюджетов) является обеспечение полной интеграции процессов в информационных системах. 


\section{ЛИТЕРАТУРА}

1. Артюхин Р. Новый этап казначейской системы система казначейских платежей и единый казначейский счет // Материалы Московского финансового форума 2021, 8 сентября 2021 г./ URL: https://youtu.be/8El5a30llhQ.

2. 0 внесении изменений в Бюджетный кодекс Российской Федерации в части казначейского обслуживания и системы казначейских платежей: Федеральный закон от 27 декабря 2019 года № 479-Ф3 (с изменениями и дополнениями) — Доступ из справочной правовой системы «КонсультантПлюс».

3. $0 б$ утверждении Порядка направления обращений высших исполнительных органов государственной власти субъектов Российской Федерации (местных администраций), органов управления государственными внебюджетными фондами о передаче (прекращении осуществления) отдельных функций финансовых органов субъектов Российской Федерации (муниципальных образований), органов управления государственными внебюджетными фондами в Федеральное казначейство и их рассмотрения Федеральным казначейством: Приказ Минфина России от 31 марта 2020 года № 50н (с изменениями и дополнениями) — Доступ из справочной правовой системы «КонсультантПлюс».

4. 0 контрактной системе в сфере закупок товаров, работ, услуг для обеспечения государственных и муниципальных нужд (ч. 5 ст. 99): Федеральный закон от 5 апреля 2013 года № 44-Ф3 (с изменениями и дополнениями). — Доступ из справочной правовой системы «КонсультантПлюс».

( Ермоленко Анна Владимировна ( ankin2002@mail.ru ). 